\title{
TAKING THE AUSPICES
}

The Budapest Daily News printed the report of the Associated Press of New York, entitling it 'New magazine about the usage of English' - then sent off directly to Cambridge asking for $E T$ on a regular basis. Under the heading 'Anybody here speak Japlish?' the London Evening Standard described ET as 'a slightly erudite glossy' that 'looks like justifying the backing of Cambridge University Press'. In a prime-time broadcast BBC Radio Four built a miscellany on the language around news of $E T$ 's official launch, while the ABC's London interview broadcast in Australia was reported by one correspondent as making her want 'to rush out and get a copy straight away'.

The worldwide media interest has been matched by a steadily increasing and widening editorial post-bag. Responses have been coming in from all over the UK and US, from Western Europe and Eastern Asia, from Qatar to Cameroon and Guadeloupe to Morocco.

What kind of responses? - Comments on contributors and content, on styles and ideas, on biographies and photographs, on usage and abusage, misprints and misconceptions, ideology and philosophy, sexual bias and spelling reform, subscription rates and availability in bookshops and bookstores. And along with it all an abundance of complimentary encouragement. The interest and enthusiasm of individuals and groups, newspapers and other magazines, publishers sending in material for review, writers offering typescripts and ideas all suggest that, as one American correspondent put it, 'you're on a winner'. Post $\mathcal{E}$ Mail across the way seeks to reflect the variety and quality of your response (especially to Jenny Cheshire in ETI!), and I would like to add here some further answers to a range of general queries and comments:

- Yes, $E T$ really is the first magazine as opposed to learned journal that C.U.P. has published in its 400 years of producing 'all manner of books'.

- Yes, ET draws on solid scholarship and language expertise (often of a highly innovative and informative nature), but in a way that reaches well beyond the groves of academe.
- No, it is not 'a plain man's [or even a plain person's] guide to correct English', if that means we want to be an Académie Anglaise, but we shall/will publish material that can help people decide for themselves about usage and trends in the language - a service that we believe many will welcome.

- No, we are not an Anglo-American plot to foist neo-imperialism on the world, and yes, we do care about small languages caught in the path of the English juggernaut.

- Yes, circulation is rising steadily, and the mechanisms are going into place to make $E T$ available at a reasonable price wherever in the world anybody wants it - but it all takes a little time and a lot of negotiation.

Time, in fact, is the essence of this issue: time and trends as the language moves towards the 21st century. Michael Swan is at the cutting edge of language teaching in Britain, while Laurence Urdang pioneered the use of computers in lexicography in the United States; Valerie Illingworth edits the Oxford Dictionary of Computing, and Tim Furniss reports on space exploration. We asked all four, therefore, to write about today's English as it shades into tomorrow's, and the results are on pages 6 to 15 .

Other features range from Canada's two literatures to Scotland's three languages by way of the geopolitics of England and Ireland. Maggie Cook writes about nonsense(?) verse, Crossworld offers prizes, ET interviews the director-general of the British Council, Lexicon looks at the diabolical dictionary-making of Ambrose Bierce, and we have a round-up of Ruppies, EuroYumpies and even hochmagandy among the drongos. Enjoy, as they say in Manhattan Yinglish.

Tom McArthur

The editorial policy of English Today is to provide a focus or forum for all sort of news and opinion from around the world. The points of view of individual writers are as a consequence their own, and do not reflect the opinion of the editorial board. In addition, wherever feasible, ET leaves unchanged the orthography (normally British or American) and the usage of individual contributors, although the editorial style of the magazine itself is that of Cambridge University Press.

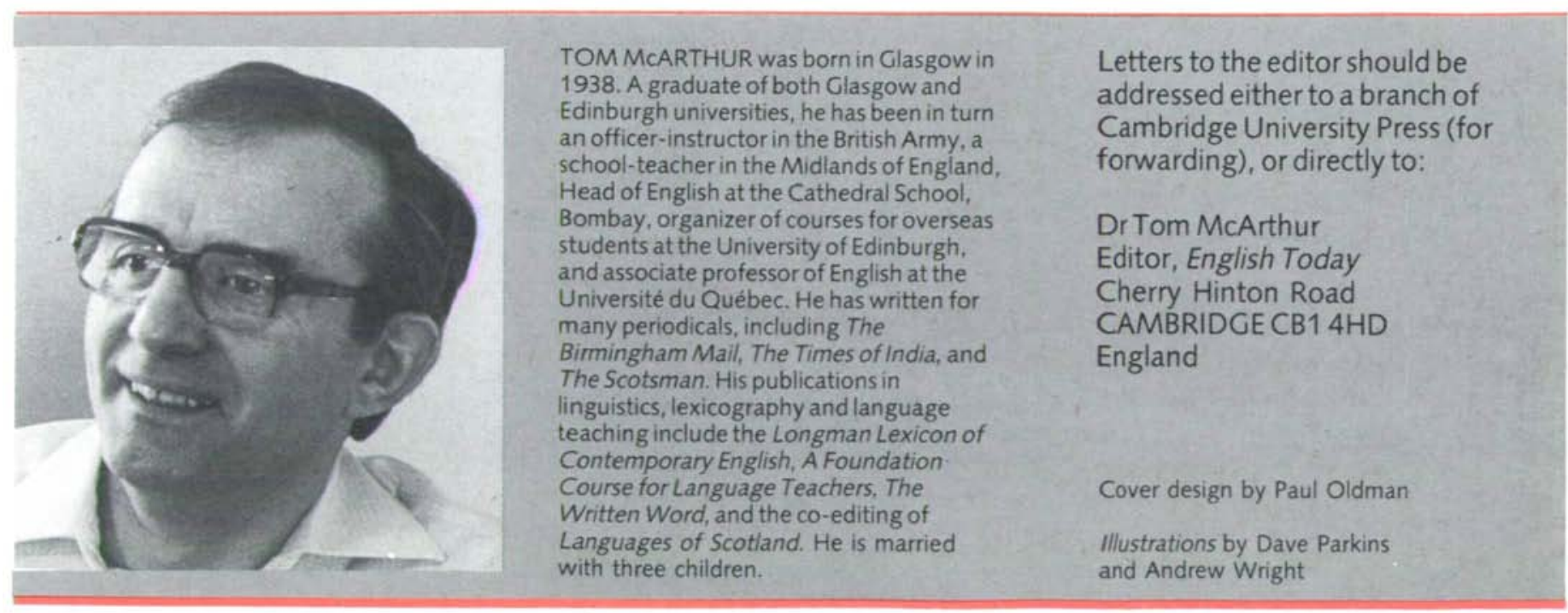

